\title{
Design, Development, and Testing of a Compact Tribocorrosion Apparatus for Biomedical Applications
}

\author{
Arman Butt • Newton B. Lucchiari Jr. • Dmitry Royhman • \\ Maria J. Runa $\cdot$ Mathew T. Mathew $\cdot$ Cortino Sukotjo • \\ Christos G. Takoudis
}

Received: 18 August 2014/Revised: 4 October 2014/Accepted: 18 November 2014/Published online: 12 December 2014

(c) Springer International Publishing AG 2014

\begin{abstract}
Orthopedic and dental implants experience the synergistic effect of wear and corrosion, i.e., tribocorrosion, which has been a major contributor to the premature failure of implants. This work focuses on the development of a compact and cost-effective tribocorrosion apparatus for the investigation of fretting and wear. The custom-built apparatus is validated with an analysis of the tribocorrosion behavior of $\mathrm{Ti}-$ $6 \mathrm{Al}-4 \mathrm{~V}$ disks in artificial saliva $\left(\mathrm{pH}=6.5, T=37^{\circ} \mathrm{C}\right)$. Electrochemical impedance spectroscopy, potentiodynamic, free potential, and potentiostatic analyses were used for electrochemical characterization of Ti-6Al-4V disks. White light interferometry and scanning electron microscopy were used to analyze wear scars on the Ti-6Al-4V disks. Total wear loss was calculated to be $12.4 \pm 1.5 \mu \mathrm{g}$, and the synergistic weight loss ratio $(0.78 \pm 0.1)$ showed that Ti-6Al-4V disks experience synergy of wear and corrosion, with wear being the dominant component.
\end{abstract}

\section{A. Butt $\cdot$ C. G. Takoudis}

Department of Bioengineering, University of Illinois at Chicago, Chicago, IL 60607, USA

N. B. Lucchiari Jr.

Department of Dentistry, Federal University of Santa Catarina, Florianópolis, Santa Catarina 88040-9000, Brazil

D. Royhman · M. J. Runa $\cdot$ M. T. Mathew

Department of Orthopedics, Rush University Medical Center, Chicago, IL 60612, USA

\section{Sukotjo}

Department of Restorative Dentistry, College of Dentistry,

University of Illinois at Chicago, Chicago, IL 60612, USA

C. G. Takoudis $(\bowtie)$

Department of Chemical Engineering, University of Illinois at Chicago, Chicago, IL 60607, USA

e-mail: takoudis@uic.edu
Keywords Tribocorrosion - Synergistic weight loss ratio - Potentiostatic test - Potentiodynamic test . Electrochemical impedance spectroscopy

\section{Introduction}

Tribocorrosion is defined as the synergistic combination of oxidation/reduction reactions and wear [1-4]. While implant integration and infection control remain priorities, poor tribocorrosion behavior of biomedical implants has continued to be a major concern [5-9]. Recently, several medical implant manufacturers issued recalls of their hip implants with complications due to tribocorrosion [10, 11]. In one case, implant failure was projected to affect $40 \%$ of implant recipients $[10,12]$. While such an extreme failure may be uncommon, weight-bearing joint replacements, such as knee and hip implants, suffer from long-term revision rates of $12 \%$ [13] and $17 \%$ [14], respectively [15-17]. The majority of failures are due to aseptic loosening [15-17]. Aseptic loosening is thought to be the result of chronic inflammatory response to implant surface debris and metal ions released as a result of tribocorrosion at the implant-bone interface [16]. While knee and hip implants may last up to 12 years on average, the life-expectancy of the US population continues to rise [14]. Consequently, replacement surgeries for dental, hip, and knee implants have seen an increase of about $100 \%$ over the past decade [18-20], especially for the 45-64 years age group [18]. The increase in life-expectancy coupled with the increase in the elderly population, and increased implantation rate highlights the importance of a longer-lasting implant.

For a comprehensive investigation of biomaterials, such as Ti6Al4V alloy (Ti-V), tribocorrosion studies are essential. For corrosion and tribology experiments, a potentiostat is used to analyze electrochemical behavior 
$[2,21]$. Investigators and research labs have attempted to modify existing tribometers or purchase commercial tribocorrosion apparatuses, and even some have attempted construction of a custom-built apparatus. While no standard exists for construction of a tribocorrosion apparatus, existing system designs can be studied to discover features important for a tribocorrosion apparatus. The main objective of this study is to develop an inexpensive, compact, and mobile tribocorrosion apparatus that is simple to use and has good repeatability.

\section{Tribocorrosion Apparatus}

In order to develop a tribocorrosion apparatus, an in-depth study of existing literature is required. The findings of the investigation and a validation pilot study are described below.

\subsection{Considerations for Tribocorrosion Apparatus Design}

A custom-built tribocorrosion apparatus offers the advantage of flexibility to reflect the needs of the investigation. Priority must be given to important functions of a tribocorrosion apparatus, while some functions may need to be sacrificed. For example, load cells for obtaining normal and friction force values can cost several hundred dollars and may not be necessary initially, but a robust motor which can run continuously for hundreds of cycles is necessary. Once a design is established, the longevity of system components is a primary concern. In particular, the motor used for tribology and the electrochemical cell used for electrochemical measurement are important components. As already mentioned, the motor needs to be able to run continuously for several hundred cycles per sample and test all the samples necessary for successful completion of the study. The electrochemical cell should not leach material into the solution and should be electrically inert. Also, the connecting wiring needs to be isolated from the solution. It is important to understand that while expensive industrial tribocorrosion apparatuses are meant to function for several years, they may not be necessary for short-term investigations. Finally, an investigator must also consider budget constraints and evolving functional needs.

\subsection{Non-uniformity in Literature}

While all tribocorrosion systems are conceptually similar, there are some design differences reported in the literature. For example, a pin or ball of various materials is used as a counter-body, which can have a unidirectional or reciprocal movement against the sample. Other designs feature the sample moving against the stationary counter-body. Furthermore, while linear reciprocating motion is common, a few systems employ a circular track, where the pin or ball moves on the sample in a continuous or intermittent circular path, with or without reciprocation [21-36]. In some cases, a warm water bath surrounds the electrochemical cell to mimic body temperature [25, 29, 33]. Major differences and similarities between the systems in literature are given in Table 1 and briefly described below.

- All of the systems incorporated a counter-body which is resistant to wear and is electrochemically inert; the counter-body was routinely inspected, cleansed, and replaced as needed [21-36]. The counter-body is required to perform in reproducible manner for every sample and therefore special care needs to be taken. Conductive materials for the counter-body, for example, would alter the electrochemical data.

- All electrochemical cells, including the sample holder, were constructed of materials resistant to corrosion, such as polyvinyl chloride (PVC) [21-23, 27, 31], Teflon [24], acrylic [34], and polypropylene [30], while many others did not mention the choice of material [25, $26,28,29,32,33,35,36]$. Similar to the considerations for the counter-body, any leached material from the electrochemical cell into the corrosion solution may alter the tribological dynamics (third-body wear) and reaction kinetics.

- Nearly all of the examined apparatuses in the literature measure frequency of pin movement using equipment such as laser diodes, photoelectric sensors, and tachometers $[21-23,25,27,31,36]$. The remainder of the systems mention control of pin movement frequency and amplitude, however, no explanation is given for how pin movement is monitored $[24,26,28-30,32-$ $35]$. In order to replicate biological phenomena, specific frequencies, length, and duration of movement are necessary. This includes, but is not limited to, teeth, knees, and hips. All of these structures experience different loads, movements, and physiological solutions.

- All systems used a combination of load cells and/or piezoelectric transducers for the measurement of normal force and frictional force [21-36]. Specifically, these components are used to ensure that a constant load is applied to the sample surface and the coefficients of friction are obtained to understand wear dynamics.

- While not mentioned specifically in all of the studies, the placement of counter and reference electrodes (CE and $\mathrm{RE}$, respectively) relative to the working electrode (WE) was vital to prevent noise and collect accurate data [21-36]. 


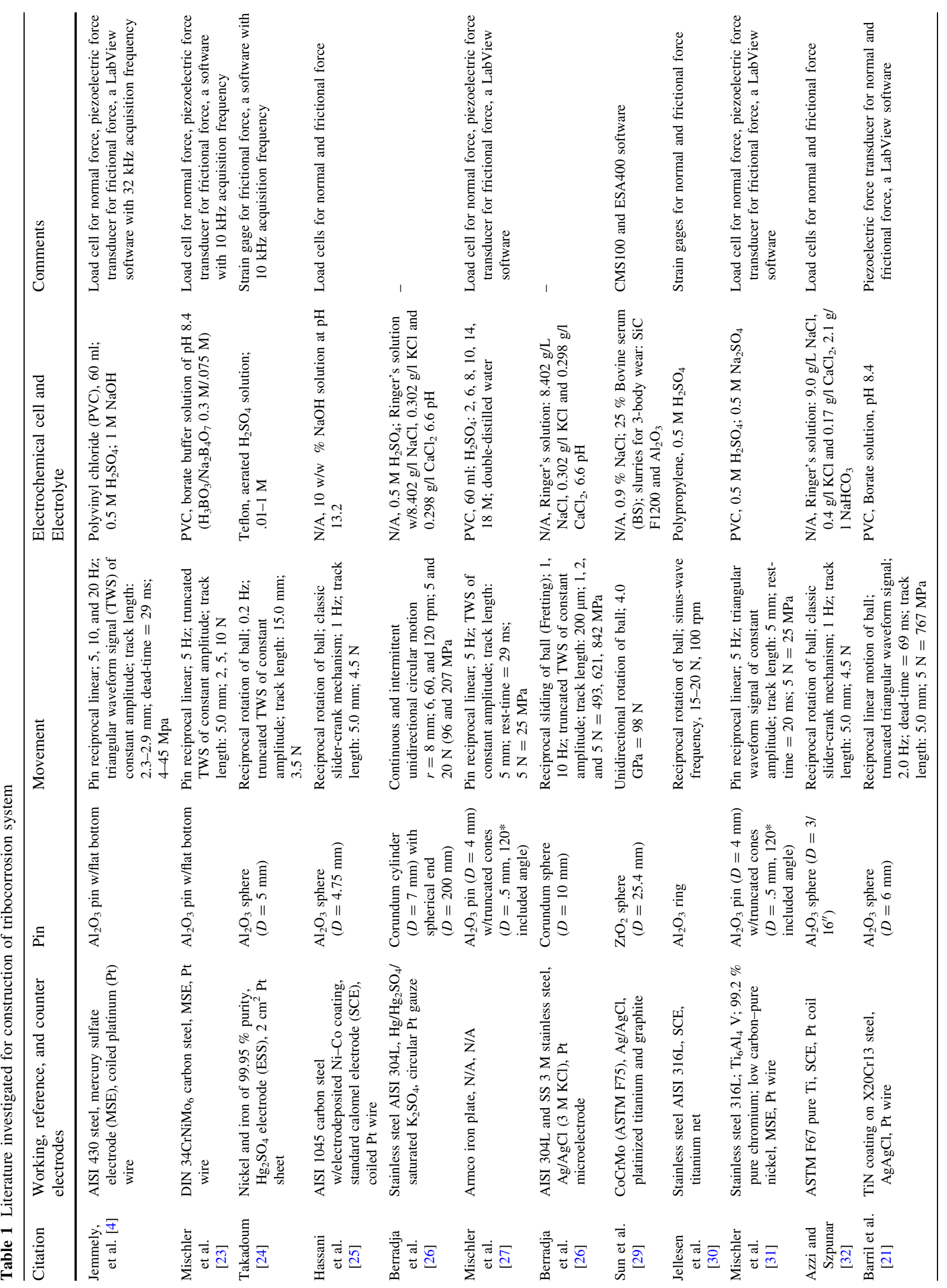




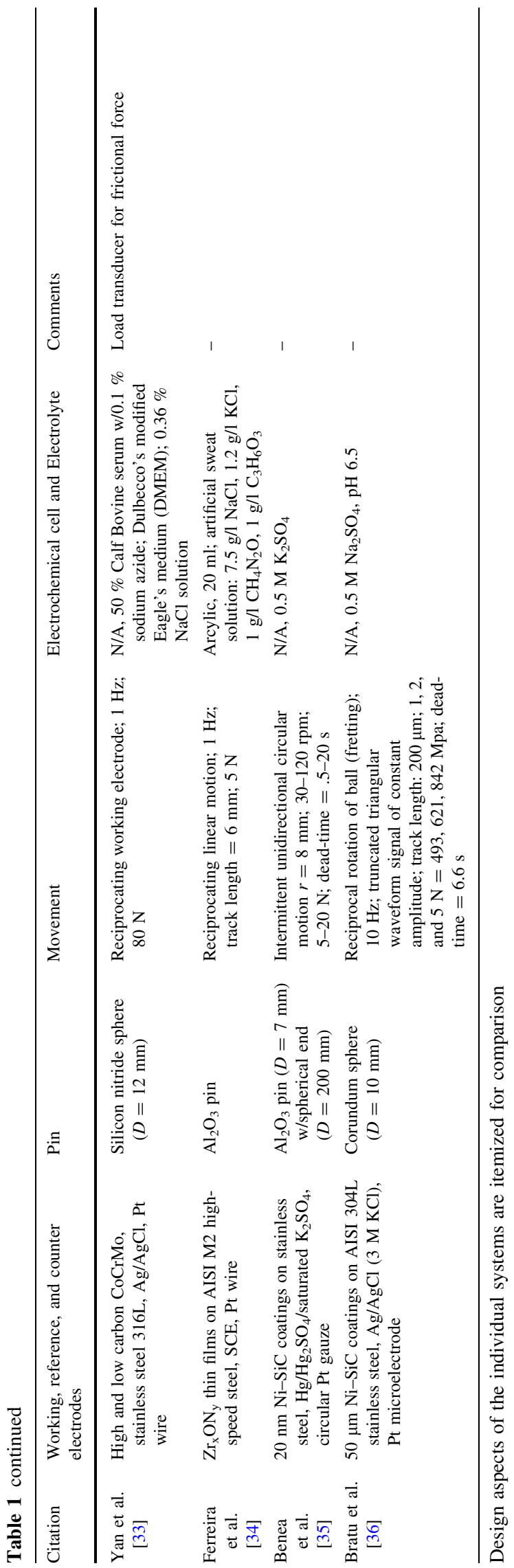

\subsection{Development of a Tribocorrosion Apparatus}

Based on literature and investigational needs, the final design of the tribocorrosion apparatus and components of the experimental setup are given in Fig. 1. Sketchup 8.0 (Google Inc., Mountain View, CA, USA) was used to render a 3-dimensional model of the tribocorrosion apparatus to feature the main components (Fig. 1b). The tribocorrosion apparatus includes (i) a motor and classic slider-crank mechanism for linear reciprocal counter-body pin movement, (ii) electrochemical cell housing the WE, $\mathrm{RE}$, and CE, and (iii) a water-jacket surrounding the electrochemical cell with input and output ports for the heated and cooled water, respectively. A variable power supply (Kepco, MPS 620 M, Flushing, NY, USA) is used to power the motor, a potentiostat (G700, Gamry, Warminster, PA, USA) was used for the electrochemical tests, and the data were analyzed using OriginPro 9.0 (OriginLab, Northampton, MA, USA). The electrochemical cell is shown in Fig. 2. Isolation of the probe connections to the WE from the corrosion solution required a screw-in method of the sample holder, where the wiring is connected from the bottom of the electrochemical cell (Fig. 2a). The electrochemical cell is surrounded by a water bath, ensuring the environment is at body temperature (Fig. 2b). The frequency of reciprocal motion is monitored by a tachometer (Digital Laser Photo Tachometer Non-Contact, Model \# DT-2234C ${ }^{+}$). The counterbody pin is mounted under a frictionless track connected to the motor (Fig. 2c). The track is mounted to a spring-loaded plate, onto which, weights are added to push the trackmounted pin onto the sample. To determine the load at the point of contact, a load cell was used for calibration. The dimensions of the apparatus are 12.5 in $(31.8 \mathrm{~cm})$ in height, 8.0 in $(20.3 \mathrm{~cm})$ in width, and 12.5 in $(31.8 \mathrm{~cm})$ in length, with a volume displacement of $0.72 \mathrm{ft}^{3}\left(.02 \mathrm{~m}^{3}\right)$, making it possible to be placed in a compact space, such as an incubator (Fig. 3). Finally, the custom-designed apparatus was constructed at a low cost, up to two orders of magnitude less than commercial systems.

\subsection{Pilot Study}

The custom-built apparatus is validated with an analysis of the tribocorrosion behavior of $\mathrm{Ti}-\mathrm{V}$ disks in artificial saliva ( $\mathrm{pH}=6.5, T=37^{\circ} \mathrm{C}$ ). For this study, potentiodynamic, free potential, and potentiostatic analyses were used for electrochemical characterization of Ti-V disks. White light interferometry and scanning electron microscopy were used to analyze wear scars on the Ti-V disks. After validation, the apparatus was used to investigate the tribocorrosion behavior of $\mathrm{Ti}-\mathrm{V}$ disks in culture media inside an incubator (Revco Scientific Inc., M \# WJ501TABA, 


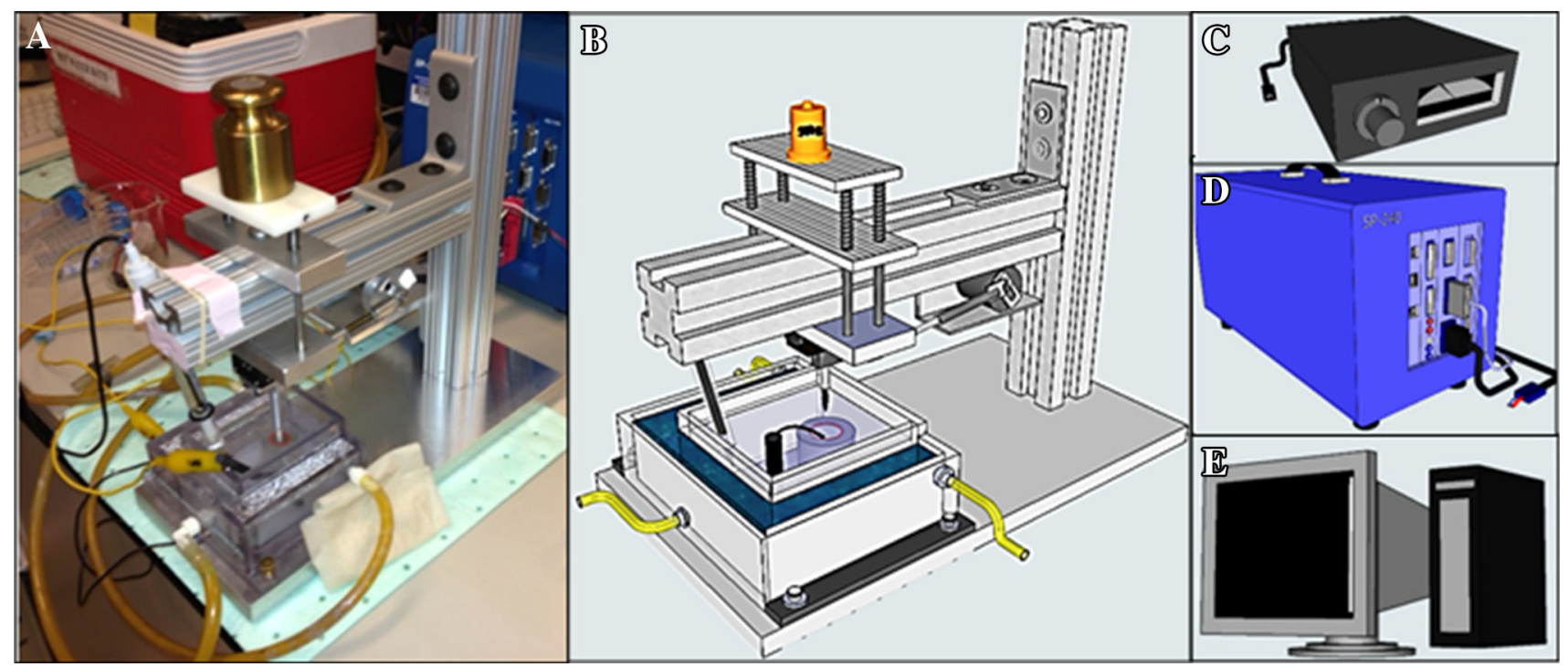

Fig. 1 Custom-built tribocorrosion apparatus: a image of the tribocorrosion apparatus, $\mathbf{b}$ rendering of the tribocorrosion apparatus, $\mathbf{c}$ power supply, d potentiostat, and e data acquisition PC using Sketchup8

Asheville, NC, USA). The culture media was used as the electrolyte consisting in alpha minimum essential medium $(\alpha$-MEM) supplemented with $10 \%$ fetal bovine serum (FBS), and $1 \%$ penicillin-strepsin, at $\mathrm{pH}$ of 7.4 and $37{ }^{\circ} \mathrm{C}$ in a humidified atmosphere of $5 \% \mathrm{CO}_{2} /$ air. As Fig. 3 shows, the apparatus is placed inside the incubator with its door closed over the electrode and motor connections. The compactness of the apparatus allows for its use to study implant materials in culture media with live cells to mimic biological conditions to study the effect of osteoblasts and bacteria on tribocorrosion behavior.

In this study, $12 \mathrm{Ti}-\mathrm{V}$ disks were cut and polished from Ti-V rods (McMaster-Carr, Elmhurst, IL, USA). The chemical composition of Ti-V alloy is given in Table 2 (McMaster-Carr). A smooth surface $\left(R_{\mathrm{a}}=10 \pm 2 \mathrm{~nm}\right)$ was achieved by (i) wet-grinding using a series of abrasive pads (\#200, 320, 400, 600, and 800; Carbimet 2, Buehler, Lake Bluff, IL, USA), (ii) polishing with a polishing cloth (TexMet, Buehler, Lake Bluff, IL, USA), diamond paste (MetaDi 9-micron, Buehler, Lake Bluff, IL, USA), and lubricant (MetaDi Fluid, Beuhler, Lake Bluff, IL, USA), and (iii) fine-polishing with a separate polishing cloth (Chemomet I, Buheler, Lake Bluff, IL, USA) with colloidal silica polishing suspension (MasterMed, Buehler, Lake Bluff, IL, USA). Polished samples were ultrasonically cleaned for $10 \mathrm{~min}$ in $70 \%$ isopropanol (Sigma Aldrich, St. Louis, MO, USA) and 10 min in deionized (DI) water (18.2 M $\Omega-\mathrm{cm}$, Barnstead NANOPure, Lake Balboa, CA, USA) and finally dried with $\mathrm{N}_{2}$ gas (Grade 4.8, $99.998 \%$, Progressive Industries, Inc., Chicago, IL, USA).

Table 3 contains the composition of artificial saliva (AS) as suggested by Liu et al. to imitate normal oral conditions [37].Artificial saliva $\mathrm{pH}=6.5(120 \mathrm{ml})$ was achieved by adding $\mathrm{NaOH}$ (basic) to the AS. To imitate the daily mastication of a person, an alumina ceramic pin was used as the counter-body with a normal force of $1.7 \mathrm{~N}$ (Hertzian contact pressure of $24 \mathrm{MPa}$, contact area of $0.071 \mathrm{~mm}^{2}$ ) and a $1 \mathrm{~Hz}$ reciprocal motion for 1,800 cycles [38-40].

As previously mentioned, a Gamry potentiostat (G300, Gamry Inc., Warminster, PA, USA) with a three-electrode configuration (American Society for Testing of Materials (ASTM) guidelines (G61 and G31-72)) was used to conduct standard corrosion tests during sliding such as potentiodynamic (PD), potentiostatic (PS), and free potential (FP) tests $(n=4 /$ group). In addition, electrochemical impedance spectroscopy (EIS) was conducted before and after sliding. A saturated calomel electrode (SCE) was used as the Reference Electrode (RE), graphite rod as the Counter Electrode (CE), and the exposed surface $\left(1.77 \mathrm{~cm}^{2}\right)$ of the Ti-6Al-4V disks as the Working Electrode (WE). The temperature of the test solution was maintained at $37 \pm 1{ }^{\circ} \mathrm{C}$. The standard protocol used for the tests consists of an initial stabilization period, a sliding period, and a final stabilization [41-44]. First, in order to understand the shift in the corrosion kinetics, potentiodynamic tests were conducted. These were followed by a series of free potential (FP) tests to monitor evolution of potential. Finally, a series of potentiostatic tests (PS) at $E_{\text {corr }}$ were conducted to monitor evolution of current. Electrochemical impendence spectroscopy (EIS) was conducted before and after sliding to examine the changes in corrosion kinetics under mechanical stimulation [3, 45]. For the investigation of tribocorrosion behavior of $\mathrm{Ti}-\mathrm{V}$ 


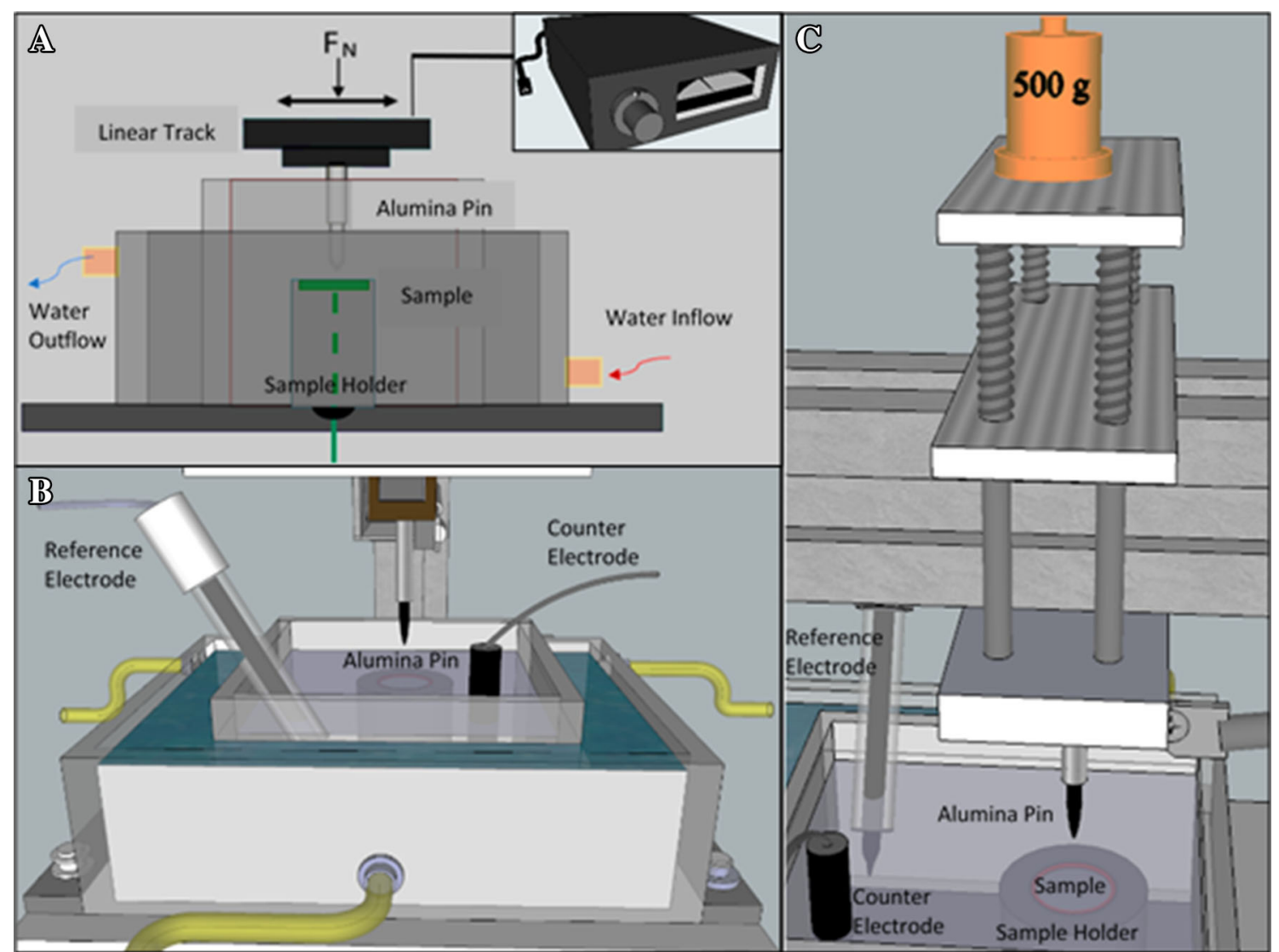

Fig. 2 Rendering of the electrochemical cell and tribometer: schematic of a working electrode connection, $\mathbf{b}$ electrochemical cell with inlet and outlets for $37{ }^{\circ} \mathrm{C}$ water bath, reference electrode (RE), counter electrode $(\mathrm{CE})=$ graphite, and working electrode $(\mathrm{WE})=\mathrm{Ti}-\mathrm{V}$, and c tribometer indicating placement of weights

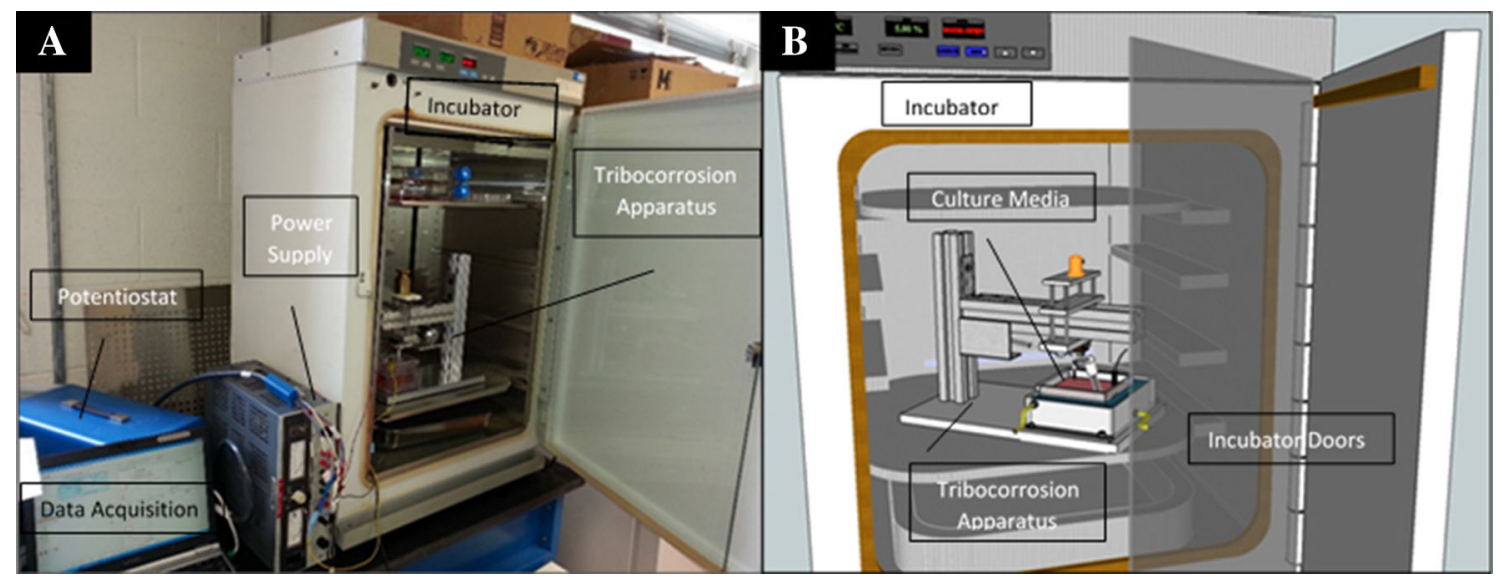

Fig. 3 Custom-built tribocorrosion apparatus placed inside an incubator: a image of the incubator setup and $\mathbf{b}$ rendering of the incubator setup

Table 2 Elemental composition of Ti-V alloy (McMaster-Carr)

\begin{tabular}{lllllll}
\hline Element & $\mathrm{Ti}$ & $\mathrm{Al}$ & $\mathrm{V}$ & Iron & Carbon & Other \\
\hline wt.\% & $88.18-90.7$ & $5.50-6.75$ & $3.5-4.5$ & $0.30 \max$ & 0.08 & $0.0-0.268$ \\
\hline
\end{tabular}


disks in culture media, a series of FP tests were conducted to monitor the evolution of potential.

A white light interferometry (WLI) microscope (Zygo New View 6300, Zygo Corporation, Middlefield, CT, USA) and ImageJ software (NIH, Bethesda, MD, USA) were used to analyze the depth, width, and length of the wear scars of the Ti-V surface after tribocorrosion. A simple model as described by Mathew et al. was used to separate the total wear loss due to corrosion and wear. Specifically, Eqs. 1-3 were used for the calculations [2, 21, 22, 43, 46-48].

$K_{\mathrm{WC}}=(2 / 3) \pi a b c D=K_{\mathrm{W}}+K_{\mathrm{C}}$,

where $K_{\mathrm{WC}}$ is the total mass loss due to wear and corrosion (tribocorrosion) and is approximated to be equivalent to half of an ellipsoid with axis $a, b$, and $c, D$ is the density of the material, $K_{\mathrm{W}}$ is the mass loss due to sliding wear, and $K_{\mathrm{C}}$ is the mass loss due to corrosion. It is assumed that corrosion outside of the wear track is negligible and therefore not considered for calculation of $K_{\mathrm{WC}}, K_{\mathrm{W}}$, and $K_{\mathrm{C}}[3,4,25,46]$. The weight loss due to corrosion can be estimated using Faraday's Law:

$K_{\mathrm{C}}=Q / Z F$

$K_{\mathrm{C}}=M I t / Z F$,

where $Q$ is the charge passed, $F$ is the Faraday's constant (96,500 $\left.\mathrm{C} \mathrm{mol}^{-1}\right), Z$ is the number of electrons involved in the corrosion process (assumed to be 2), $I$ is the total current, $t$ is the total exposure time, and $M$ is the atomic mass of the material or equivalent weight. Based on these calculations, relative contributions of corrosion and wear to the wear scar can be estimated by Eq. 4 [48, 49].

Synergistic ratio $=K_{\mathrm{c}} / K_{\mathrm{w}}$,

where the ratio determines whether the weight loss is dominated by wear, corrosion, or due to a combination of wear and corrosion: $K_{\mathrm{c}} / K_{\mathrm{w}} \leq 0.1$ for wear dominated, $K_{\mathrm{c}} / K_{\mathrm{W}}>10.0$ for corrosion dominated, $0.1 \leq K_{\mathrm{c}} / K_{\mathrm{w}} \leq 1.0$

Table 3 Artificial saliva components as described by Liu et al. [37]

\begin{tabular}{lll}
\hline Artificial saliva solution & & Concentration \\
\hline Potassium chloride & $\mathrm{KCl}$ & $0.4 \mathrm{~g} / \mathrm{L}$ \\
Sodium chloride & $\mathrm{NaCl}$ & $0.4 \mathrm{~g} / \mathrm{L}$ \\
Calcium chloride anhydrous & $\mathrm{CaCl}_{2} \cdot 2 \mathrm{H}_{2} \mathrm{O}$ & $0.9 \mathrm{~g} / \mathrm{L}$ \\
Urea & $\mathrm{CO}\left(\mathrm{NH}_{2}\right)_{2}$ & $1 \mathrm{~g} / \mathrm{L}$ \\
$\begin{array}{l}\text { Monosodium phosphate } \\
\text { anhydrous (buffer component) }\end{array}$ & $\mathrm{NaH}_{2} \mathrm{PO}_{4} \cdot 2 \mathrm{H}_{2} \mathrm{O}$ & $0.7 \mathrm{~g} / \mathrm{L}$ \\
$\begin{array}{l}\text { Sodium sulfide anhydrous (buffer } \\
\quad \text { component) }\end{array}$ & $\mathrm{Na}_{2} \mathrm{~S} \cdot 9 \mathrm{H}_{2} \mathrm{O}$ & $0.005 \mathrm{~g} / \mathrm{L}$ \\
$\begin{array}{l}\text { For controlling pH } \\
\end{array}$ & $\mathrm{NaOH}$ & Add as \\
& & needed \\
\hline
\end{tabular}

for wear as main component, and $1.0 \leq K_{\mathrm{c}} / K_{\mathrm{W}} \leq 10.0$ for corrosion as main component [48, 49].

A scanning electron microscope (SEM) (JEOL JSM6490 LV, Oxford Instruments, Oxford, UK) was used for characterization of surface morphology.

\section{Results and Discussion}

\subsection{Electrochemical Analysis}

Potentiodynamic (PD), free potential (FP), and potentiostatic (PS) tests were conducted for validation of the tribocorrosion apparatus based on examination of literature. Electrochemical impedance spectroscopy was conducted before and after sliding (Fig. 4) and the oxide is modeled after a modified Randle's circuit which places the polarization resistance $\left(R_{\mathrm{P}}\right)$ in parallel with constant phase element (CPE) of the oxide film, in series with the solution resistance $\left(R_{\mathrm{S}}\right)$ [50]. As reported in the literature, the oxide film did not change significantly before and after sliding. [43, 44] $R_{\mathrm{S}}$ is resistance of the electrolyte between the sample and reference electrode; $R_{\mathrm{P}}$ is the charge transfer resistance at the sample surface and electrolyte interface; $\mathrm{CPE}$ is used in place of a capacitance due to the inhomogeneity of the passive layer [44]. Before sliding, average $R_{\mathrm{S}}, R_{\mathrm{P}}$, and CPE are calculated to be $267.9 \pm 11.4 \Omega$, $1.1 \pm 0.16 \times 10^{7} \Omega$, and $2.6 \pm 0.4 \times 10^{-5} \mathrm{Fs}^{(\alpha-1)}$, respectively. After sliding, average $R_{\mathrm{S}}, R_{\mathrm{P}}$, and CPE are calculated to be $269.1 \pm 6.9 \Omega, \quad 1.2 \pm 0.11 \times 10^{7} \Omega$, and $2.6 \pm$ $0.4 \times 10^{-5} \mathrm{Fs}^{(\alpha-1)}$, respectively. These values are similar to those reported in literature [43, 44]. However, Mathew et al. reported $R_{\mathrm{P}}$ values to be much lower [43].

\subsubsection{Potentiodynamic Scan}

Figure 5a shows a corrosion-only PD curve of a $\mathrm{Ti}-\mathrm{V}$ sample in Artificial Saliva (AS) of $\mathrm{pH}=6.5$, and Fig. $5 \mathrm{~b}$ shows a tribocorrosion PD scan of a Ti-V sample in AS of $\mathrm{pH}=6.5$. The observed $E_{\text {corr }}$ (corrosion potential), which indicates the readiness of a material to corrode, is similar to values reported for $\mathrm{Ti}-\mathrm{V}$ alloy in literature in the range of -0.5 to $-1.0 \mathrm{~V}[1,44,51-54]$. Compared to corrosiononly PD scan, the $E_{\text {corr }}$ of $\mathrm{Ti}-\mathrm{V}$ alloy during tribocorrosion is slightly higher $(-0.8$ vs. $-0.6 \mathrm{~V}$. Upon initiation of sliding, the current increased drastically (cathodic shift) and reached a fluctuating range of 1 and $100 \mu \mathrm{A}$ as the passive layer was repeatedly formed and destroyed during sliding. This range of current, also known as passivation current ( $\left.I_{\text {PASS }}\right)$, is similar to those reported in the literature [1, 43, 44, 52-54]. The fluctuating current can be explained as follows. The current increases (cathodic shift) as the passive film is destroyed by the sliding alumina pin [54]. 
As the pin passes and the worn surface is allowed to interact with the surrounding solution, the surface is repassivated and the current decreases (anodic shift) until the pin slides over the area again to repeat the cycle [54]. As the trend in the graph shows, the depassivation and repassivation process are not in equilibrium; instead, the overall trend is a cathodic shift, where the sliding is causing more depassivation than repassivation. As Fig. 5a shows, neutral $\mathrm{pH}$ corrosion-only PD tests of $\mathrm{Ti}-\mathrm{V}$ alloy is known to result in a stable $\mathrm{I}_{\text {PASS }}$ region with no fluctuation or increase in the current [23, 48, 49, 51]. However, under mechanical stimulation (Fig. 5b), the $\mathrm{I}_{\text {PASS }}$ region is slightly higher during tribocorrosion and continues to shift to higher current regions during sliding [54]. Comparing corrosion-only and tribocorrosion PD scans, it can be seen that the Ti-V alloy has poor tribocorrosion behavior, more specifically, the Ti-V alloy has poor wear resistance.

\subsubsection{Evolution of Potential}

An evolution of potential curve, obtained from free potential tests (FP), of $\mathrm{Ti}-\mathrm{V}$ sample in $\mathrm{AS}$ of $\mathrm{pH}=6.5$ is shown in Fig. 6a. Figure $6 \mathrm{~b}$ and $\mathrm{c}$ show the changes in potential during the beginning and end of sliding. It was difficult to compare these results to literature due to the differences in the normal force and contact area used. These parameters affect the contact pressure, which the surface experiences during sliding, and therefore the wear [3]. In the present study, the potential increased during sliding from OCP to the cathodic direction in the range of -0.7 and $-0.9 \mathrm{~V}$ and stabilized after cessation of sliding. Such a trend is reported in several studies [41, 45, 49, 53-

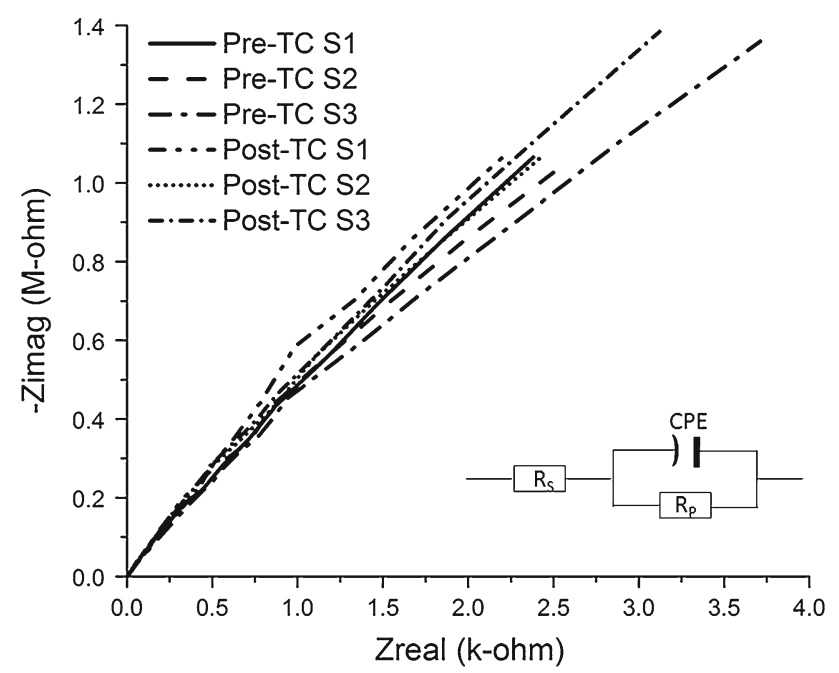

Fig. 4 Electrochemical impedance spectroscopy before and after sliding. Inset Modified Rande's circuit is used to model the oxide film. The graph shows no significant change in the oxide composition before and after sliding
55]. This drop and recovery in potential indicates the initiation and cessation of sliding, respectively, of alumina pin on Ti-V alloy samples. Such a drop in potential during sliding indicates the removal of the passive film, which protects the metal from corrosion [46]. Initiation of sliding does not result in an instantaneous decrease in potential. Instead, a gradual decrease in potential is observed over several cycles of sliding until a dynamic equilibrium of depassivation and repassivation is reached (Fig. 6b). The cessation of sliding does not result in a sudden recovery in voltage either. Instead, a gradual decrease is observed over $300 \mathrm{~s}$ of rest until OCP is reached (Fig. 6c). Comparatively, Fig. 7 shows the evolution of potential of $\mathrm{Ti}-\mathrm{V}$ disks in culture media placed in an incubator. The evolution of potential follows the same pattern as described before, that is, potential drops rapidly during sliding and gradually increases to OCP once sliding ceases. However, OCP before sliding, the potential drop during sliding, and OCP after sliding are all lower than the potential values observed for the validation portion. The lower potential values indicate that the culture media may have a negative effect on the tribocorrosion behavior of the Ti-V surface. Although cells were not included at this stage, the preliminary results may explain why there are discrepancies between the predicted life-span of implants and the actual in vivo tribocorrosion behavior. While tribocorrosion studies have been studied in water baths to mimic body temperature involving culture media and cells, the compactness of the apparatus (volume displacement of $0.72 \mathrm{ft}^{3}$ $\left.\left(.02 \mathrm{~m}^{3}\right)\right)$ makes it possible for the investigation of tribocorrosion behavior of implant materials with cells in an incubator to better mimic in vivo conditions.

\subsubsection{Potentiostatic Scan}

A PS curve of $\mathrm{Ti}-\mathrm{V}$ sample in $\mathrm{AS}$ of $\mathrm{pH}=6.5$ is shown in Fig. 8a-c which shows the changes in current during the beginning and end of sliding. This test was carried out at $E_{\text {corr }}$ which was obtained from the PD scans. While PD scans were easier to compare with literature, PS data depend on the type of counter-body material, contact area, normal force, frequency, and length of sliding. Similar to FP scans, PS scans were difficult to compare with literature due to the various parameters which differ from study to study; however, several comparable observations can be made. In studies involving neutral $\mathrm{pH}$, the current increased (cathodic) dramatically during sliding in tribocorrosion PS tests [43, 45, 46, 53, 56]. The increase and decrease in current indicates the initiation and cessation, respectively, of sliding of alumina pin counter-body on $\mathrm{Ti}-$ $\mathrm{V}$ samples. Initiation of sliding does not result in an instantaneous increase in current; however, rather a gradual increase is observed over several cycles of sliding until a 

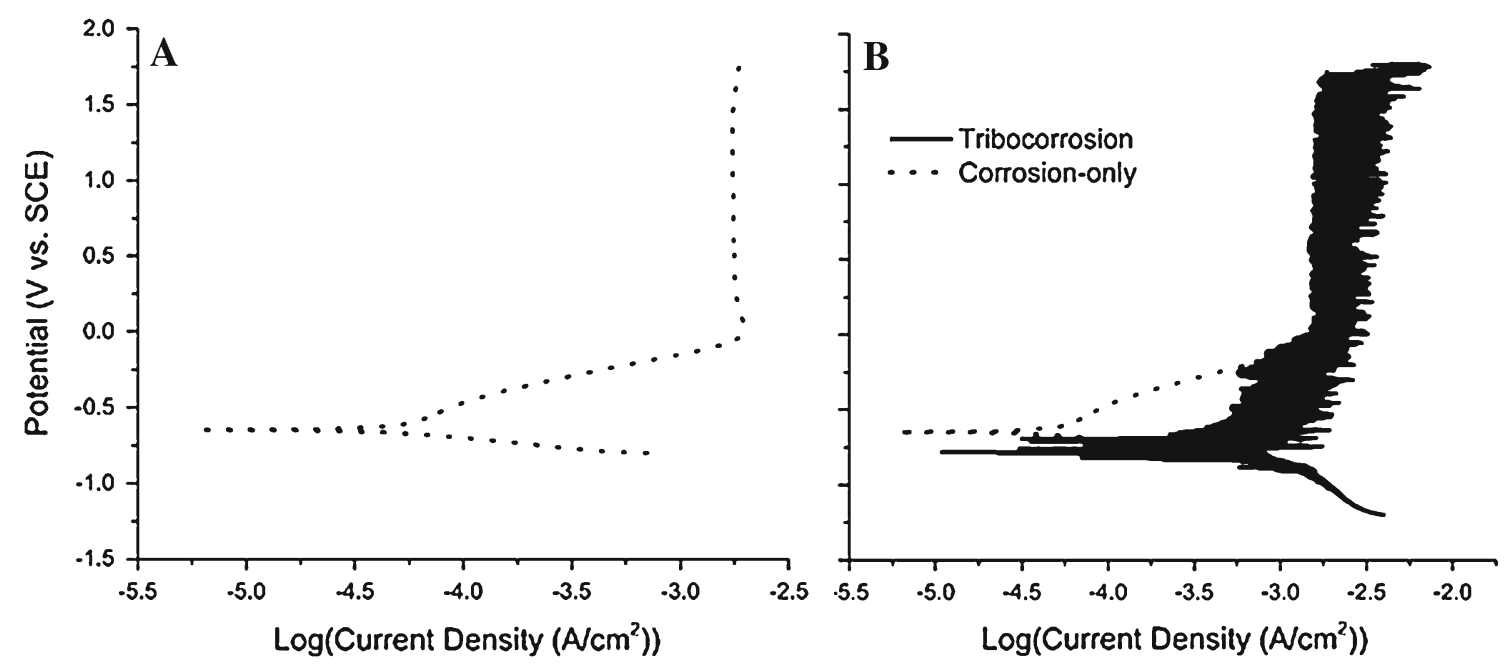

Fig. 5 a Potentiodynamic (PD) scan of a control Ti-V sample for corrosion experiment in $\mathrm{pH}=6.5$ solution. b Comparison of corrosion and tribocorrosion PD scans of a Ti-V sample in $\mathrm{pH}=6.5$ solution
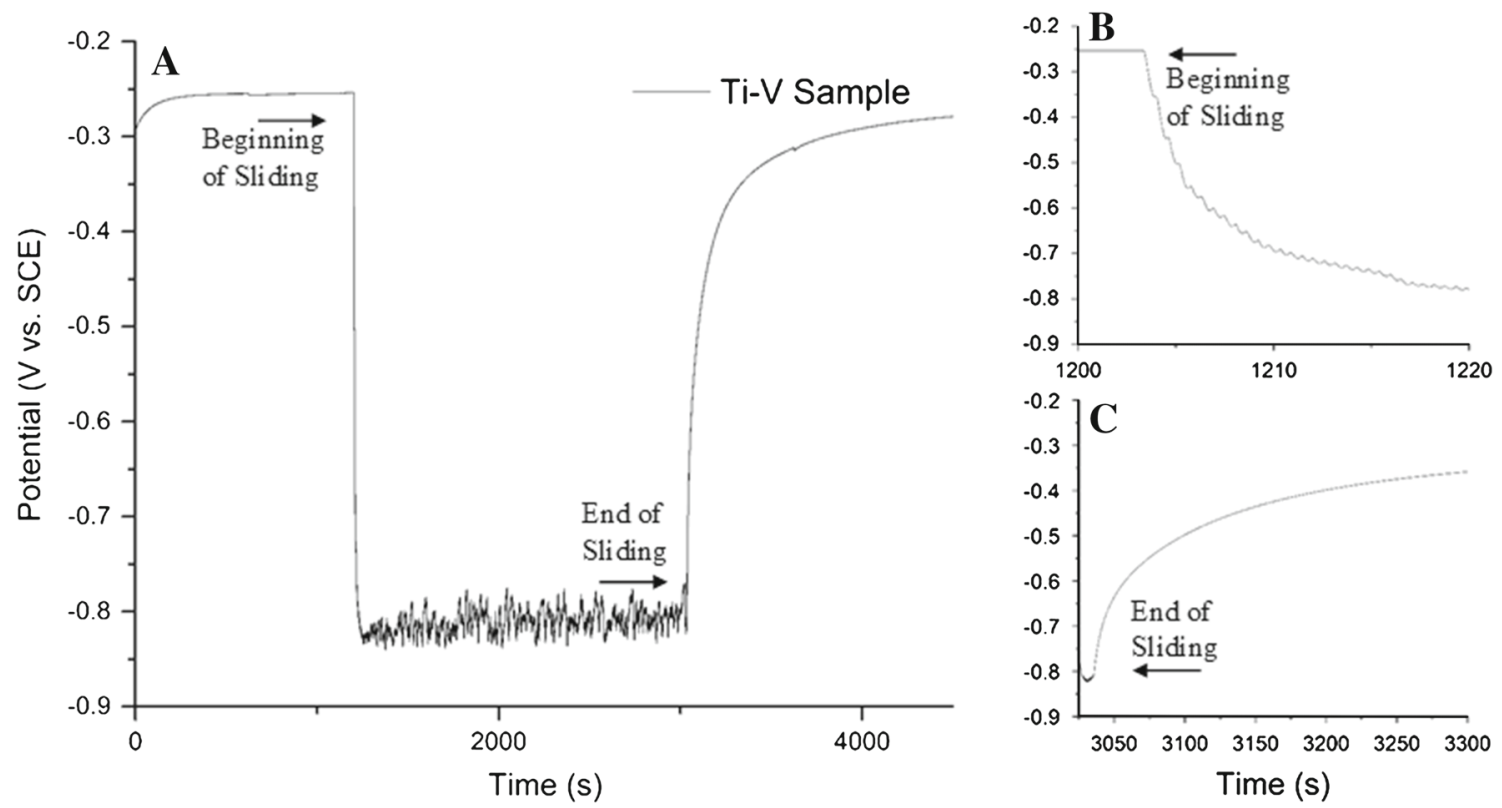

Fig. 6 a An evolution of potential curve of a control Ti-V sample for tribocorrosion experiment in $\mathrm{pH}=6.5$ solution. $\mathbf{b}$ Initiation of sliding results in a gradual increase in cathodic voltage observed over several

dynamic equilibrium of depassivation and repassivation is reached. In the present study, the current fluctuated between 4.0 and $8.0 \mu \mathrm{A}$ during sliding (Fig. 8a). The current continues to shift to higher current regions during sliding, which is indicative of depassivation [29, 41, 43, 46]. As the sliding of the alumina pin damages the film, repassivation does not occur completely before the pin returns to the same area, therefore the trend is toward depassivation. Additionally, the repassivated oxide layer may not be thick enough and therefore is entirely removed once the pin slides over the area. After sliding is halted, the seconds and cessation of sliding results in a gradual decrease in cathodic voltage observed over $300 \mathrm{~s}$ of rest until OCP is reached

current decreases (anodic) and is indicative of repassivation of the damaged area [29, 47]. The cessation of sliding does not result in a sudden decrease in current, however, rather a gradual decrease of current is observed over a several seconds until pre-sliding current values are reached.

\subsection{Surface Characterization}

Figure 9 shows the WLI intensity map image of the wear scar region of a Ti-V sample with a $20 \times$ magnification lens and an image zoom of $2 \times$. The oblique plot of the 


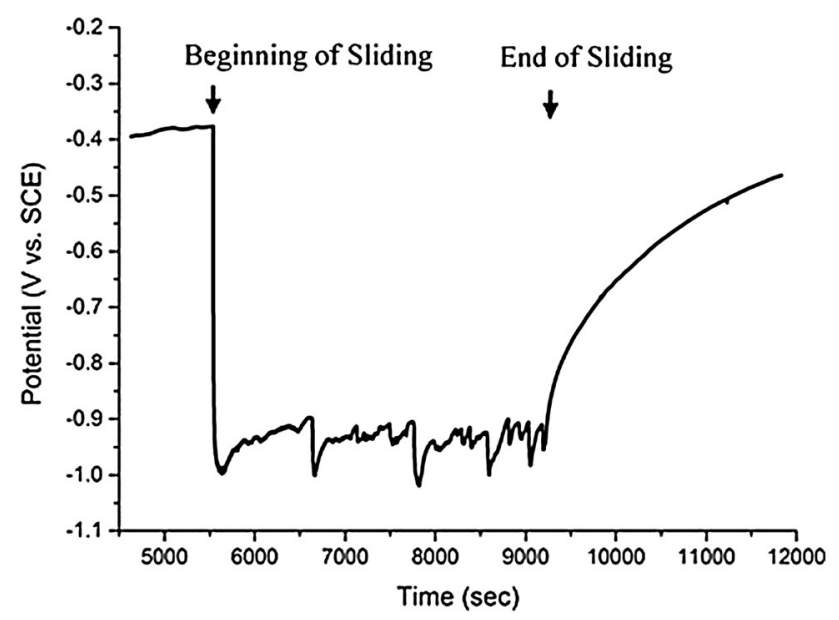

Fig. 7 An evolution of potential scan of a control Ti-V sample for tribocorrosion experiment in culture media in an incubator. Alpha minimum essential medium ( $\alpha$-MEM) was supplemented with $10 \%$ fetal bovine serum (FBS), and $1 \%$ penicillin-strepsin, at $\mathrm{pH}$ of 7.4 and $37{ }^{\circ} \mathrm{C}$ in a humidified atmosphere of $5 \% \mathrm{CO}_{2} /$ air

wear scar region, such as the one shown in Fig. 10, was used with ImageJ software to measure the depth, width, and length of the wear scars. For potentiostatic scans, the depth, width, and length of the wear scars were measured to be $13.7 \pm 2.6,202 \pm 25$, and $1880 \pm 61 \mu \mathrm{m}$, respectively. For free potential scans, the depth, width, and length of the wear scars were measured to be $14.0 \pm 2.5$, $212 \pm 10$, and $1810 \pm 91 \mu \mathrm{m}$, respectively. No significant difference was observed between potentiostatic and free potential scans. Figure 11 shows the SEM images of the wear scar of the three Ti-V samples with $\times 60$ and $\times 300$ magnification. As the SEM images show, all three electrochemical tests produced similar wear scars with pitting, grooves, and deformation due to compression and shear. The uniformity of the wear scar length, width, and depth suggest that the mechanical components of the tribocorrosion apparatus behave in a consistent manner.

\subsection{Wear and Corrosion Loss}

Using the measured length and width of the wear scar and the assumption that the wear scar resembles an ellipsoid, the total wear loss $\left(K_{\mathrm{WC}}\right)$ is calculated to be $12.4 \pm 1.5$ and $12.0 \pm 0.9 \mu \mathrm{g}$ for free potential and potentiostatic scans, respectively, with no significant difference. Using Eq. 2 and the current values obtained from potentiostatic scan in Fig. $8 \mathrm{a}, K_{\mathrm{C}}$ is calculated to be $5.25 \pm 0.30 \mu \mathrm{g}$. $K_{\mathrm{W}}$ is calculated to be $6.75 \pm 1.0 \mu \mathrm{g}$, and the estimated synergistic weight loss ratio $\left(K_{\mathrm{c}} / K_{\mathrm{w}}\right)$ is calculated to be $0.78 \pm 0.1$. For the synergistic weight loss ratio between 0.1 and 1.0, a combination of wear and corrosion occurs where wear may play a larger part. This may be explained with the Archard wear equation

$Q=K W L / H$,

where $Q$ is the total wear volume produced, $W$ is the total normal load, $H$ is the hardness of the softest contacting surfaces, $K$ is a constant, and $L$ is the sliding distance. As
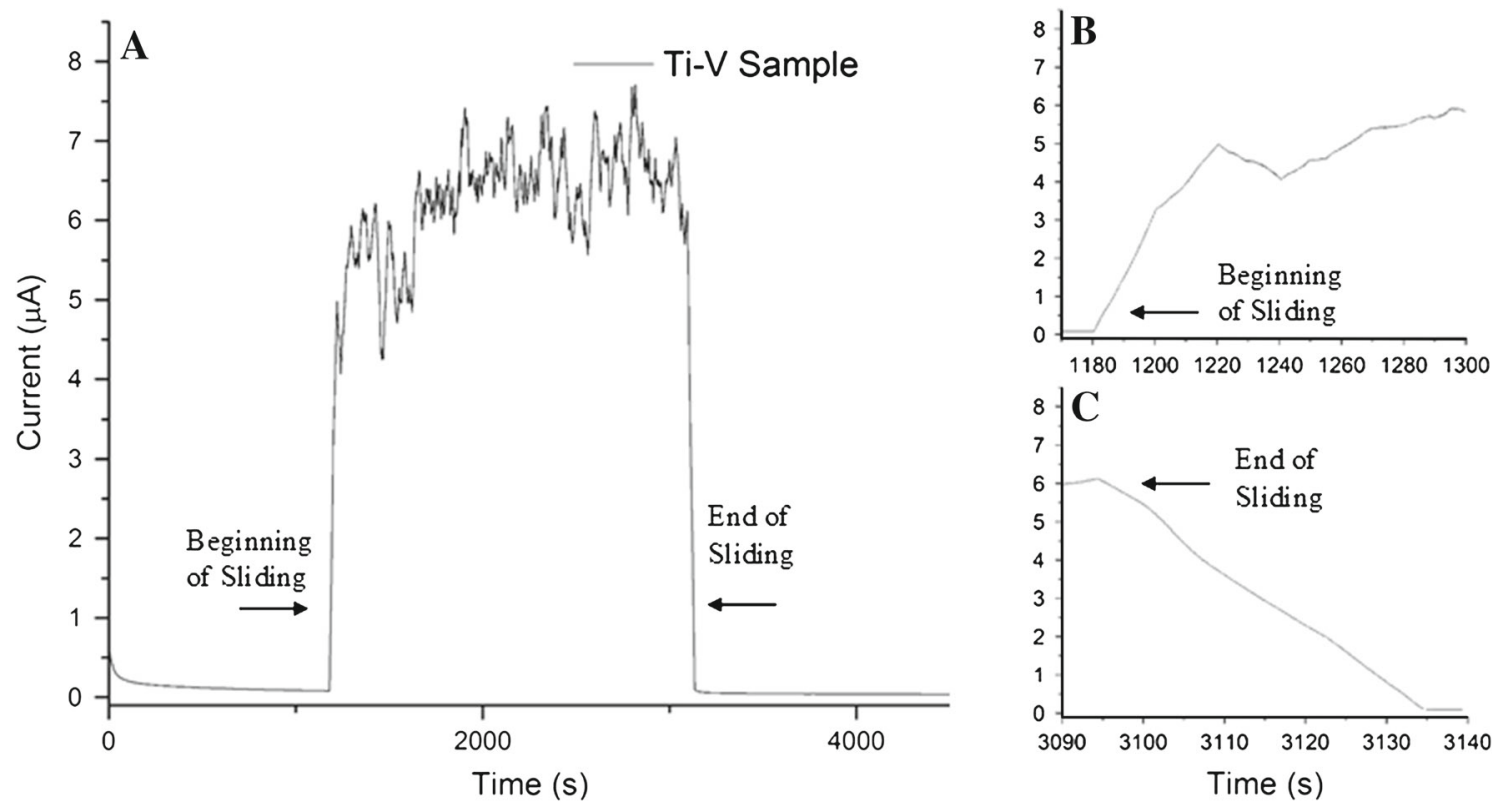

Fig. 8 a Potentiostatic scan of a control Ti-V sample for tribocorrosion experiment in $\mathrm{pH}=6.5$ solution. $\mathbf{b}$ Initiation of sliding results in a gradual increase in current observed over a period of sliding and c cessation of sliding results in a gradual decrease in current observed over a period of rest until equilibrium is reached 


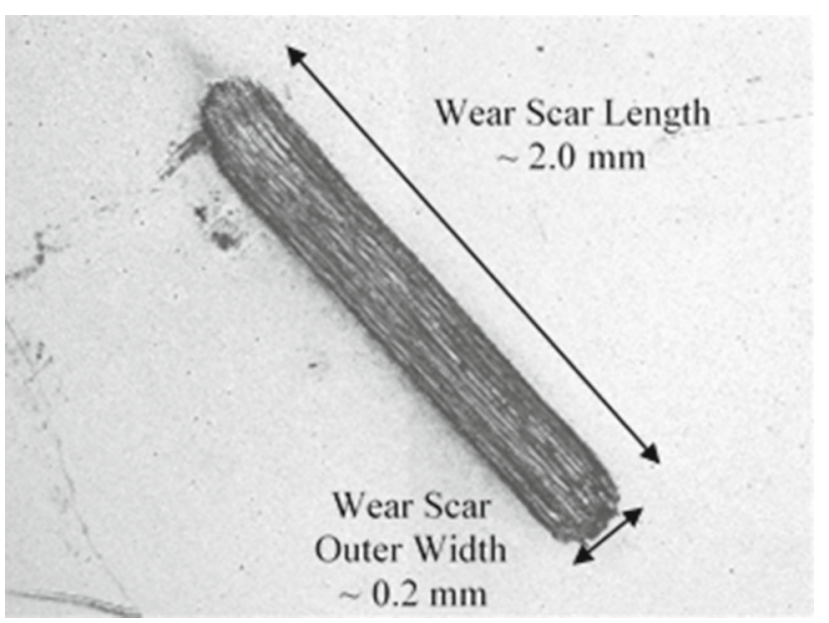

Fig. 9 WLI intensity map image of the wear scar region of a Ti-V sample with a $20 \times$ magnification lens and an image zoom of $2 \times$ after tribocorrosion $\mathrm{pH}=6.5$ solution. Wear scar dimensions were measured as $\sim 2.0 \mathrm{~mm}$ in length and $\sim 0.20 \mathrm{~mm}$ in width using ImageJ software

per Archard's equation, the weight loss is inversely proportional to the hardness; Ti-V is observed to be a soft material and therefore would experience greater weight loss due to tribocorrosion [57]. While exact comparison of weight loss results was not possible with corresponding values reported in the literature, there are some observed similarities. Alves et al., for example, reported wear scar depth of $16.0 \pm 5.66 \mu \mathrm{m}$ for tribocorrosion on $\mathrm{CP}-\mathrm{Ti}$ (similar density to that of Ti-V alloy) using a normal force of $2 \mathrm{~N}$, artificial saliva of $37^{\circ} \mathrm{C}$, alumina ball counter-body of $10 \mathrm{~mm}$ diameter, $3 \mathrm{~mm}$ displacement of $2 \mathrm{~Hz}$ and $720 \mathrm{~s}$ duration [58]. Licausi et al. reported a weight loss of $384 \mu \mathrm{g}$ for tribocorrosion of Ti-V alloy using alumina ball of diameter $6 \mathrm{~mm}$, a load of $5 \mathrm{~N}$, and artificial saliva of $\mathrm{pH}$ 6.0 and $37{ }^{\circ} \mathrm{C}$ [53]. However, the path of sliding was circular, longer, and the contact stress was considerably higher, which may explain the greater weight loss [53]. Manhabosco et al. reported a wear scar depth of almost
$30 \mu \mathrm{m}$ under tribocorrosive conditions using an alumina ball of diameter $5 \mathrm{~mm}$ and normal load, sliding frequency, and sliding distance of $4 \mathrm{~N}, 1 \mathrm{~Hz}$, and $8 \mathrm{~mm}$, respectively, in a phosphate-buffered saline (PBS) solution $\left(37^{\circ} \mathrm{C}\right.$, $\mathrm{pH}=7.1$ ) [54]. Similar to Licausi et al., the experimental method of Manhabosco et al. included greater contact pressure which may explain the deeper scar depth. Runa et al. reported a wear loss of $13.6 \pm 3.25 \mu \mathrm{g}$ for tribocorrosion using an alumina ball of diameter $10 \mathrm{~mm}$ and normal load of $1 \mathrm{~N}$ and sliding distance of $2 \mathrm{~mm}$ and $1 \mathrm{~Hz}$ in a PBS solution $\left(37{ }^{\circ} \mathrm{C}, \mathrm{pH}=7.5\right)$ [50]. Due to similar contact area, wear scar length, and load, Runa et al. had similar results to those detailed in this study [50].

\subsection{Scope and Future Directions}

Further experiments need to be conducted in AS solutions of acidic and basic $\mathrm{pH}$ to mimic the changes that occur in the oral environment such as infection and food consumption. In addition, by increasing the normal load, orthopedic conditions can be mimicked with synovial fluid at acidic and neutral $\mathrm{pH}$ for infection and normal conditions, respectively. For both dental and orthopedic environments, both sliding and fretting mechanical stimulation need to be considered for a full understanding of tribocorrosion of the entire implant. While sliding experiments of a few millimeters in displacement mimic wear in joints, fretting experiments of approximately $100 \mu \mathrm{m}$ or less in displacement may better mimic micro-movements between implant components, such as implant-abutment or crownabutment, or within implant-bone interfaces such as the stem-femur or screw-mandible interfaces. Further improvements to the tribocorrosion apparatus can also be made.

- It was noticed that in some experiments, the edges of the truncated alumina pin may have caused the pin to become jammed in areas of the wear track where roughness was introduced during sliding. Therefore, a

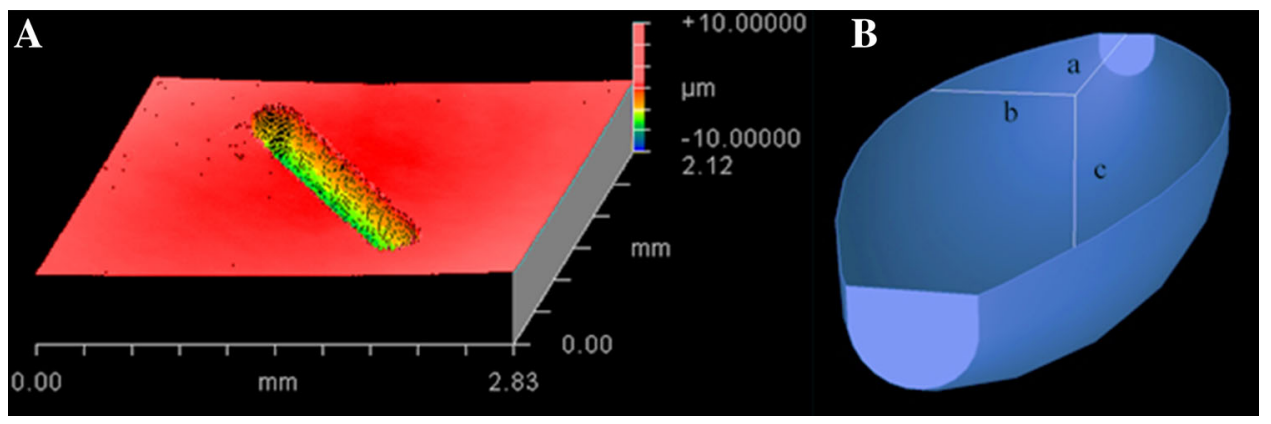

Fig. 10 a Wear scar depth profile obtained using WLI of control Ti$\mathrm{V}$ sample after tribocorrosion in $\mathrm{pH}=6.5$ solution. Roughness values were measured as $R_{\mathrm{A}}=1.04 \mu \mathrm{m}, R_{\mathrm{RMS}}=2.02 \mu \mathrm{m}$, and $\mathrm{PV}=$
$16.6 \mu \mathrm{m}$. b Using the wear scar PV value, length, and width, an ellipsoid volume approximation is used to calculate the volume of material lost due to tribocorrosion 
Fig. 11 Scanning electron microscopy (SEM) images of wear scars of Ti-V surfaces under a free potential, b potentiodynamic, and c potentiostatic tribocorrosion conditions. Magnifications of the images at $\times 60$ and $\times 300$ and direction of reciprocating alumina pin counter-body are shown
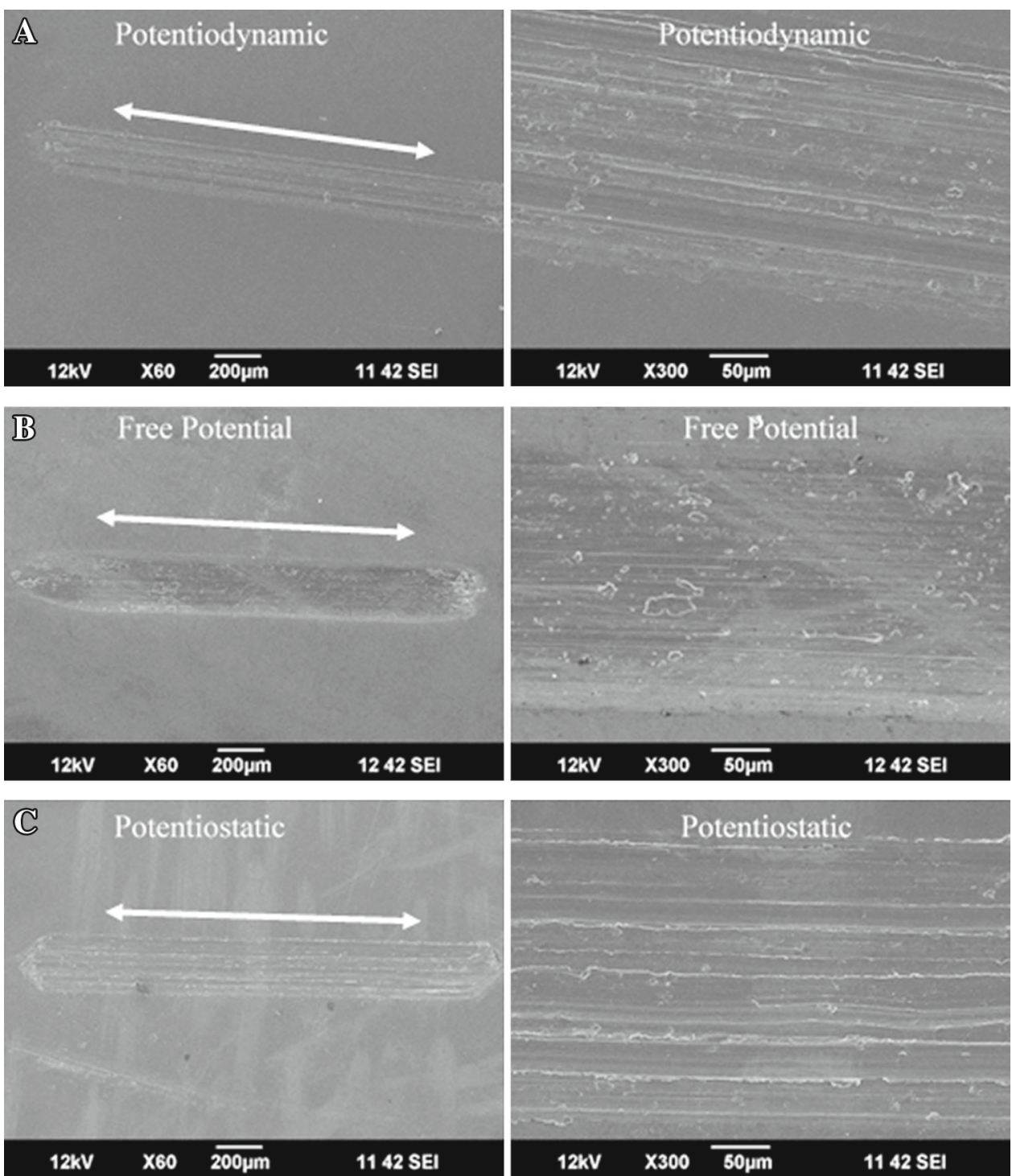

cylindrical or spherical surface without edges may provide smoother sliding.

- In addition, a spherical or cylindrical contact surface would provide a point or line contact, respectively, which would generate the required contact pressure using a lower load. Lower loads would decrease the workload on the motor used for reciprocating movement and therefore prolong its use.

- The electrochemical cell volume needs to be decreased as the current version requires a large volume of corrosion solution, which can become costly and burdensome to replace.

- While the current pin mechanism is permanently in place above the sample, and the sample holder is removed to replace samples, a hinged alumina pin holder which may be swung away from or onto the sample may allow for greater degree of freedom for removing and replacing the sample, respectively.

- Finally, it was noticed in one of the WLI images that the alumina pin had jumped its original track and formed a parallel secondary track. A shorter alumina counter-body, therefore, would provide for a more stable movement, and therefore consistent wear tracks.

\section{Conclusion}

This work demonstrates the feasibility of designing, developing, and building a compact and inexpensive tribocorrosion system. A pilot study was conducted to investigate the tribocorrosion behavior in artificial saliva and a preliminary study involving cell media in an 
incubator. The construction of a tribocorrosion system requires a detailed examination of existing systems and this study offers an analysis of the needs obtained from literature. The results of the tribocorrosion study of the Ti-V alloy validated the system when compared to the tribocorrosion behavior reported in literature. Using WLI data and Faraday's Law, it is observed that the overall trend of the Ti-V alloy is toward depassivation of the surface due to tribocorrosion with wear as the leading component. The use of the system can now be expanded to include fretting and sliding investigations of experimental surface modifications of Ti-V alloy and other metals in dental and orthopedic environments. In addition, the system proves to be suitable for tribocorrosion studies in an incubator to investigate the effects of cells on implant surfaces. Finally, a few additional changes are suggested to improve the design and development of a versatile tribocorrosion apparatus.

Acknowledgments The authors would like to gratefully acknowledge Dr. Wimmer (Director, wear testing lab, Rush University Medical Center) for providing the laboratory facility for this study and the National Science Foundation for the partial financial support (CBET \#1067424 and EEC \#1062943).

Conflict of interest On behalf of all authors, the corresponding author states that there is no conflict of interest.

\section{References}

1. Chen J, Yan FY, Chen BB, Wang JZ (2013) Assessing the tribocorrosion performance of Ti-6Al-4V, 316 stainless steel and Monel K500 alloys in artificial seawater. Mater Corros 64(5):394-401. doi:10.1002/maco.201106249

2. Landolt D, Mischler S, Stemp M, Barril S (2004) Third body effects and material fluxes in tribocorrosion systems involving a sliding contact. Wear 256(5):517-524. doi:10.1016/S00431648(03)00561-1

3. Mathew MT, SrinivasaPai P, Pourzal R, Fischer A, Wimmer MA (2009) Significance of tribocorrosion in biomedical applications: overview and current status. Adv Tribol 2009:1-12. doi:10.1155/ 2009/250986

4. Jemmely P, Mischler S, Landolt D (2000) Electrochemical modeling of passivation phenomena in tribocorrosion. Wear 237(1):63-76. doi:10.1016/S0043-1648(99)00314-2

5. Metal-on-metal hip implants: FDA safety communication. Div Small Manuf Int Consum Assist 2013

6. Health C for D and R. Safety communications-FDA safety communication: metal-on-metal hip implants 2013. http://www. fda.gov/medicaldevices/safety/alertsandnotices/ucm335775.htm. Accessed 1 Nov 2013

7. FDA's MedWatch Safety Alerts (2013) U.S. Food Drug Adminstration 2013. http://www.fda.gov/forconsumers/consumer updates/ucm340655.htm. Accessed 10 Feb 2014

8. Kux L (2012) Orthopaedic and rehabilitation devices panel of the medical devices advisory committee meeting announcement. U.S. Food Drug Adminstration 2012. http://www.fda.gov/advi sorycommittees/calendar/ucm297884.htm. Accessed 10 Feb 2014
9. Bozic KJ, Lau E, Ong K et al (2014) Risk factors for early revision after primary total hip arthroplasty in Medicare patients. Clin Orthop Relat Res 472(2):449-454. doi:10.1007/s11999-0133081-9

10. Health C for D and R. Safety Communications-Updated FDA safety communication: Stryker Neptune waste management systems 2013. http://www.fda.gov/MedicalDevices/Safety/Alert sandNotices/ucm322771.htm. Accessed 1 Nov 2013

11. Class 2 Recall DePuy ASR Resurfacing Femoral Heads. Adm. U. S. Food Drug 2011. http://www.accessdata.fda.gov/scripts/ cdrh/cfdocs/cfres/rescollection_2.cfm?id=96075\&create_dt=201103-24. Accessed 2 Oct 2014

12. Meier B. Maker aware of $40 \%$ failure in hip implant-NYTimes.com. New York Times 2013. http://www.nytimes.com/ 2013/01/23/business/jj-study-suggested-hip-device-could-fail-inthousands-more.html?_r=0

13. Fawzi N (2012) Knee replacement statistics. http://www.healthline. com/health/total-knee-replacement-surgery/statistics-infographic

14. Bozic KJ, Harry ER, Berry J, Khaled J, Saleh M, Durbhakula SM (2004) Modes of failure in revision hip and knee replacement. http://www.cdc.gov/nchs/ppt/icd9/att_TJR_oct04.ppt

15. Narkbunnam R, Chareancholvanich K (2012) Causes of failure in total knee arthroplasty. J Med Assoc Thai 95(5):667-673. http:// www.ncbi.nlm.nih.gov/pubmed/22994026. Accessed 13 Jan 2014

16. Abu-Amer Y, Darwech I, Clohisy JC (2007) Aseptic loosening of total joint replacements: mechanisms underlying osteolysis and potential therapies. Arthritis Res. Ther. 9(Suppl 1):S6. doi:10. 1186/ar2170

17. Gallo J, Konttinen YT, Goodman SB et al (2012) Aseptic loosening of total hip arthroplasty as a result of local failure of tissue homeostasis. In: Fokter SK (ed) Recent advances in arthroplasty. InTech, Rijeka, pp 321-362

18. Statistics NC for H. Health, United States, 2011: With Special Feature on Socioeconomic Status and Health 2012

19. Haswell M (2009) Clinical debate dental implants: a different perspective Part one. Implant Pract. 2(1):44-57

20. Kurtz SM, Ong KL, Lau E, Bozic KJ (2014) Impact of the economic downturn on total joint replacement demand in the United States: updated projections to 2021. J Bone Joint Surg Am 96(8):624-630. doi:10.2106/JBJS.M.00285

21. Barril S, Mischler S, Landolt D (2001) Triboelectrochemical investigation of the friction and wear behaviour of TiN coatings in a neutral solution. Tribol Int 34(9):599-608. doi:10.1016/ S0301-679X(01)00052-4

22. Jemmely P, Mischler S, Landolt D (1999) Tribocorrosion behaviour of $\mathrm{Fe}-17 \mathrm{Cr}$ stainless steel in acid and alkaline solutions. Tribol Int 1999(32):295-303

23. Mischler S, Spiegel A, Landolt D (1999) The role of passive oxide films on the degradation of steel in tribocorrosion systems. Wear 225-229:1078-1087. doi:10.1016/S0043-1648(99)00056-3

24. Takadoum J (1996) The influence of potential on the tribocorrosion of nickel and iron in sulfuric acid solution. Corros Sci 38(4):643-654. doi:10.1016/0010-938X(95)00155-D

25. Hassani S, Raeissi K, Azzi M, Li D, Golozar MA, Szpunar JA (2009) Improving the corrosion and tribocorrosion resistance of $\mathrm{Ni}-\mathrm{Co}$ nanocrystalline coatings in $\mathrm{NaOH}$ solution. Corros Sci 51(10):2371-2379. doi:10.1016/j.corsci.2009.06.026

26. Berradja A, Déforge D, Nogueira RP, Ponthiaux P, Wenger F, Celis J-P (2006) An electrochemical noise study of tribocorrosion

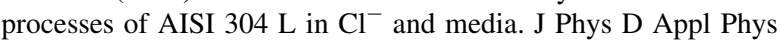
39(15):3184-3192. doi:10.1088/0022-3727/39/15/S08

27. Mischler S, Rosset E, Stachowiak GW, Landolt D (1993) Effect of sulphuric acid concentration on the rate of tribocorrosion of iron. Wear 167(2):101-108. doi:10.1016/0043-1648(93)90314-C

28. Berradja A, Bratu F, Benea L, Willems G, Celis J-P (2006) Effect of sliding wear on tribocorrosion behaviour of stainless steels in a 
Ringer's solution. Wear 261(9):987-993. doi:10.1016/j.wear. 2006.03.003

29. Sun D, Wharton JA, Wood RJK (2009) Abrasive size and concentration effects on the tribo-corrosion of cast CoCrMo alloy in simulated body fluids. Tribol Int 42(11-12):1595-1604. doi:10. 1016/j.triboint.2009.03.018

30. Jellesen MS, Hilbert LR (2007) A block-on-ring tribocorrosion setup for combined electrochemical and friction testing 2007:115-127. doi:10.1002/tt

31. Mischler S, Debaud S, Landolt D (1998) Wear-accelerated corrosion of passive metals in tribocorrosion systems. J Electroanal Soc 145(3):750-758

32. Azzi M, Szpunar JA (2007) Tribo-electrochemical technique for studying tribocorrosion behavior of biomaterials. Biomol Eng 24(5):443-446. doi:10.1016/j.bioeng.2007.07.015

33. Yan Y, Neville A, Dowson D, Williams S (2006) Tribocorrosion in implants-assessing high carbon and low carbon $\mathrm{Co}-\mathrm{Cr}-\mathrm{Mo}$ alloys by in situ electrochemical measurements. Tribol Int 39(12):1509-1517. doi:10.1016/j.triboint.2006.01.016

34. Ferreira SC, Ariza E, Rocha LA et al (2006) Tribocorrosion behaviour of $\mathrm{ZrO}_{\mathrm{x}} \mathrm{N}_{\mathrm{y}}$ thin films for decorative applications. Surf Coatings Technol 200(22-23):6634-6639. doi:10.1016/j.surfcoat. 2005.11.083

35. Benea L, Wenger F, Ponthiaux P, Celis JP (2009) Tribocorrosion behaviour of $\mathrm{Ni}-\mathrm{SiC}$ nano-structured composite coatings obtained by electrodeposition. Wear 266(3-4):398-405. doi:10. 1016/j.wear.2008.04.018

36. Bratu F, Benea L, Celis J-P (2007) Tribocorrosion behaviour of $\mathrm{Ni}-\mathrm{SiC}$ composite coatings under lubricated conditions. Surf Coatings Technol 201(16-17):6940-6946. doi:10.1016/j.surfcoat. 2006.12.027

37. Liu C, Chu PK, Lin G, Yang D (2007) Effects of Ti/TiN multilayer on corrosion resistance of nickel-titanium orthodontic brackets in artificial saliva. Corros Sci 49(10):3783-3796. http:// www.sciencedirect.com/science/article/pii/S0010938X07001059. Accessed 21 Jan 2014

38. Hidaka O, Iwasaki M, Saito M, Morimoto T (1999) Influence of clenching intensity on bite force balance, occlusal contact area, and average bite pressure. J Dent Res 78(7):1336-1344. doi:10. 1177/00220345990780070801

39. Harada K, Ohkura K (2000) Measure of bite force and occlusal contact area before and after bilateral sagittal split ramus osteotomy of the mandible using a new pressure-sensitive device: a preliminary report. J Oral Maxillofac Surg 58(4):370-373

40. Kumagai H, Suzuki T, Hamada T, Sondang P, Fujitani M, Nikawa $H$ (1999) Occlusal force distribution on the dental arch during various levels of clenching. $J$ Oral Rehabil 26(12):932-935. http://www.ncbi.nlm.nih.gov/pubmed/10620156

41. Mathew MT, Uth T, Hallab NJ, Pourzal R, Fischer A, Wimmer MA (2011) Construction of a tribocorrosion test apparatus for the hip joint: validation, test methodology and analysis. Wear 271(9-10):2651-2659. doi:10.1016/j.wear.2011.01.085

42. Roy M, Sundararajan G, Stack MM et al (2008) $\mathrm{TiC}_{\mathrm{x}} \mathrm{O}_{\mathrm{y}}$ thin films for decorative applications: tribocorrosion mechanisms and synergism. Tribol Int 41(7):603-615. doi:10.1016/j.triboint.2007.11.011

43. Mathew MT, Abbey S, Hallab NJ, Hall DJ, Sukotjo C, Wimmer MA (2012) Influence of $\mathrm{pH}$ on the tribocorrosion behavior of $\mathrm{CpTi}$ in the oral environment: synergistic interactions of wear and corrosion. J Biomed Mater Res B Appl Biomater 100(6):16621671. doi:10.1002/jbm.b.32735
44. Barão VAR, Mathew MT, Assunção WG, Yuan JC-C, Wimmer MA, Sukotjo C (2012) Stability of cp-Ti and Ti-6Al-4V alloy for dental implants as a function of saliva $\mathrm{pH}$-an electrochemical study. Clin Oral Implants Res 23(9):1055-1062. doi:10.1111/j. 1600-0501.2011.02265.x

45. Shukla AK, Balasubramaniam R, Bhargava S (2005) Properties of passive film formed on $\mathrm{CP}$ titanium, $\mathrm{Ti}-6 \mathrm{Al}-4 \mathrm{~V}$ and $\mathrm{Ti}-$ $13.4 \mathrm{Al}-29 \mathrm{Nb}$ alloys in simulated human body conditions. Intermetallics 13(6):631-637. doi:10.1016/j.intermet.2004.10.001

46. Jiang J, Stack MM, Neville A (2002) Modelling the tribo-corrosion interaction in aqueous sliding conditions. Tribol Int 35(10):669-679. doi:10.1016/S0301-679X(02)00058-0

47. Landolt D, Mischler S, Stemp M (2001) Electrochemical methods in tribocorrosion: a critical appraisal. Electrochim Acta 46(24-25):3913-3929. doi:10.1016/S0013-4686(01)00679-X

48. Stack MM, Jawan H, Mathew MT (2005) On the construction of micro-abrasion maps for a steel/polymer couple in corrosive environments. Tribol Int 38(9):848-856. doi:10.1016/j.triboint. 2005.02.013

49. Wood RJK (2007) Tribo-corrosion of coatings: a review. J Phys D Appl Phys 40(18):5502-5521. doi:10.1088/0022-3727/40/18/ S10

50. Runa MJ, Mathew MT, Rocha LA (2013) Tribocorrosion response of the Ti6Al4V alloys commonly used in femoral stems. Tribol Int 68:85-93. doi:10.1016/j.triboint.2013.09.022

51. Shahba RMA, Ghannem WA, El-shenawy AE (2011) Corrosion and inhibition of Ti-6Al-4V alloy in $\mathrm{NaCl}$ solution. Int J Electrochem 6:5499-5509

52. Iwabuchi A, Lee JW, Uchidate M (2007) Synergistic effect of fretting wear and sliding wear of Co-alloy and Ti-alloy in Hanks' solution. Wear 263(1-6):492-500. doi:10.1016/j.wear.2007.01. 102

53. Licausi MP, Igual Muñoz A, Borrás VA (2013) Tribocorrosion mechanisms of Ti6Al4V biomedical alloys in artificial saliva with different pHs. J Phys D Appl Phys 46(40):404003. doi:10. 1088/0022-3727/46/40/404003

54. Manhabosco TM, Tamborim SM, dos Santos CB, Müller IL (2011) Tribological, electrochemical and tribo-electrochemical characterization of bare and nitrided Ti6Al4V in simulated body fluid solution. Corros Sci 53(5):1786-1793. doi:10.1016/j.corsci. 2011.01.057

55. Sivakumar B, Kumar S, Sankara Narayanan TSN (2011) Fretting corrosion behaviour of Ti-6Al-4V alloy in artificial saliva containing varying concentrations of fluoride ions. Wear 270(3-4):317-324. doi:10.1016/j.wear.2010.09.008

56. Barril S, Mischler S, Landolt D (2004) Influence of fretting regimes on the tribocorrosion behaviour of Ti6Al4V in $0.9 \mathrm{wt} . \%$ sodium chloride solution. Wear 256(9-10):963-972. doi:10.1016/ j.wear.2003.11.003

57. Royhman D, Yuan JC, Shokuhfar T, Takoudis C, Sukotjo C, Mathew MT (2013) Tribocorrosive behaviour of commonly used temporomandibular implants in a synovial fluid-like environment: Ti-6Al-4V and CoCrMo. J Phys D Appl Phys 46(40):404002. doi:10.1088/0022-3727/46/40/404002

58. Alves SA, Bayón R, Igartua A, Saénz de Viteri V, Rocha LA (2013) Tribocorrosion behaviour of anodic titanium oxide films produced by plasma electrolytic oxidation for dental implants. Lubr Sci. doi:10.1002/1s.1234 